\title{
Crohn's Disease Activity Index and Vienna Classification - Is It Worthwhile to Calculate before Surgery?
}

\author{
M. Rentsch ${ }^{a}$ A. Beham ${ }^{b} \quad$ H.J. Schlitt ${ }^{b} \quad$ K.W. Jauch ${ }^{a}$ \\ Departments of Surgery, ${ }^{a}$ Ludwig-Maximilians University, Klinikum Grosshadern, Munich, and \\ ${ }^{b}$ University of Regensburg, Regensburg, Germany
}

\section{Key Words}

Crohn's disease $\cdot$ Crohn's disease activity index $\cdot$ Vienna

classification - Surgery

\begin{abstract}
Background: Crohn's disease (CD) patients with increased disease activity may reveal an increased risk for perioperative complications. The 'Crohn's disease activity index' (CDAl) and the 'Vienna classification' (VC) were developed for standardized disease activity estimations. The significance of these scores to predict extent, type and early outcome of surgery in CD patients was analyzed. Methods: In 179 surgically treated CD patients, the CDAI and VC were assessed from a prospective database. Relations of the scores with $C D$ risk factors, type, number, location and complications of surgery were analyzed. Results: VC behavior and location subtypes were associated with distinct types of surgery (i.e. 'strictureplasty' in 'stricturing disease', 'colon surgery' in 'colon involvement'), but not with surgery type and extent or outcome. Surgery extent (i.e. with 5 vs. 3 'surgical sites' $425 \pm 25$ vs. $223.3 \pm 25)$ and complications (357.1 \pm 36.9 (with) vs. $244.4 \pm 13$ (without)) were associated with elevated CDAl levels; however, nicotine abuse remained the only significant risk factor for perioperative complications after
\end{abstract}

M. Rentsch and A. Beham contributed equally to this work. multiple logistic regression. Conclusion: The significance of VC or CDAI for predicting the extent of surgery or complications is limited. None of the tested variables except preoperative nicotine abuse influenced the likelihood for perioperative complications.

Copyright $\odot 2006$ S. Karger AG, Basel

\section{Introduction}

More than two thirds of patients with Crohn's disease (CD) require surgery during their lifetime [1]. This situation is made more serious by an increased risk for perioperative complications and re-operations among these patients when compared to a general patient population. For this reason, a preoperative score, which would allow the prediction of the extent of surgery required, the perioperative risk, and the likelihood of disease recurrence would be extremely valuable [2].

Quantification and scoring systems, such as the CD activity index (CDAI) of Best and the Vienna classification (VC) [3-5] (fig. 1) have been introduced. These are intended for the estimation of $\mathrm{CD}$ severity in clinical practice, mainly for evaluation of conservative, medical treatment $[3,6-8]$. Whereas the VC aims to identify patient subgroups with increased risk factors, such as age at disease onset (A), location (L) and behavior characteristics (B) [5, 9], the CDAI is a calculated index, combining patients vital 


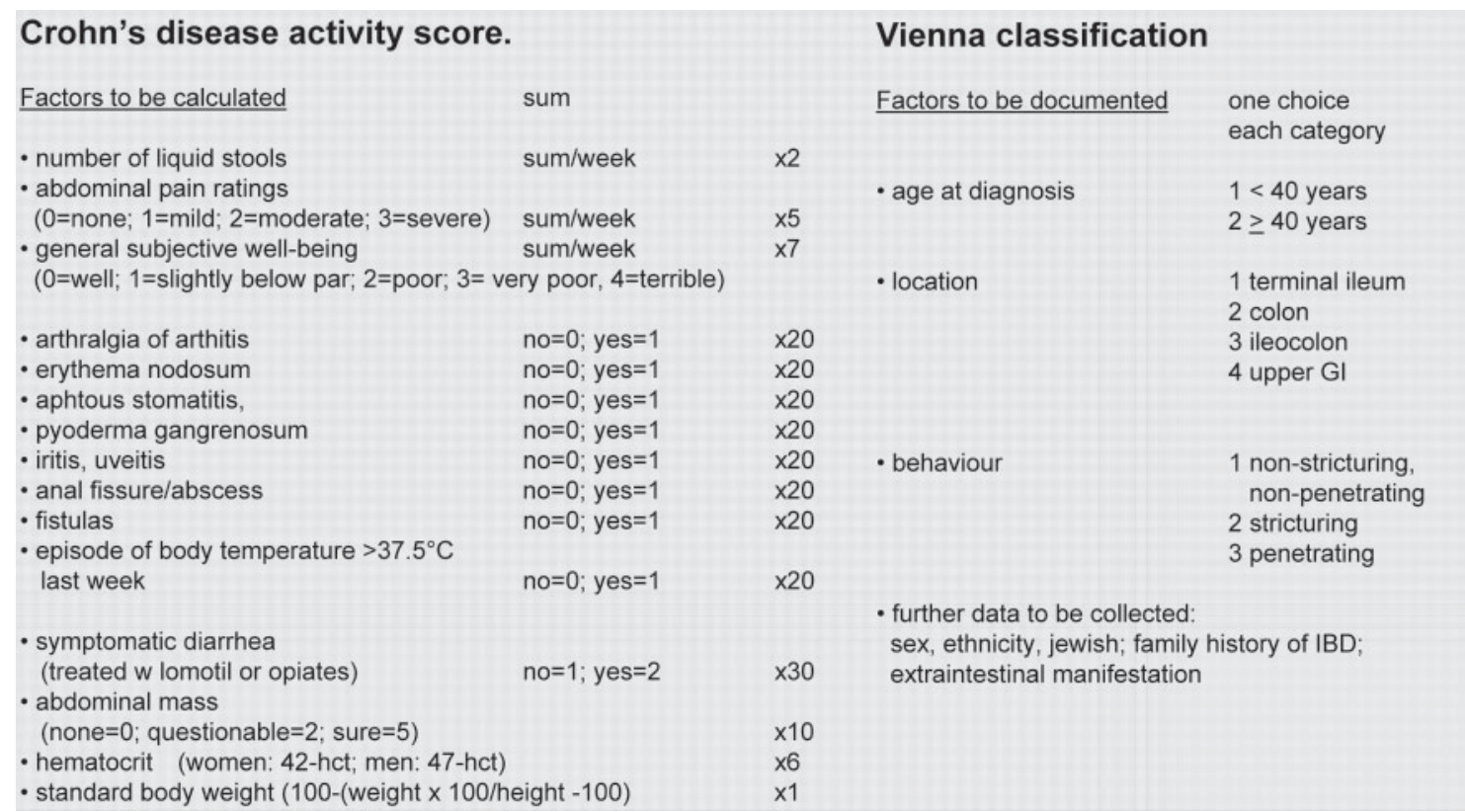

Fig. 1. Overview of both analyzed CD scoring systems. Whereas the CDAI represents clinical and subjective patient data reflecting the disease activity, the VC theoretically would allow conclusions on disease activity by identifying risk groups according to their macroscopic disease appearance (stricturing, perforating, and involvement of the upper GI tract).

parameters (i.e. temperature, body weight, white blood cell count), clinical findings (abscess/fistula, abdominal mass, body weight/temperature) and medical history (extraintestinal symptoms), reflecting general disease activity. It may be misleading to apply these two indices to decision making involving patient's awaiting surgery. In the preoperative environment, clinical parameters may be altered by previous drug treatment [10-12], changes in the disease pattern may occur [9], and diagnostic findings may underestimate the true extent of the disease [13]. Therefore, the aim of the present study is to analyze the accuracy of both scores in predicting the intra-operative extent of the disease, the amount and technique of surgical therapy required, and early postoperative outcome.

\section{Methods}

The study population consisted of patients referred for surgical treatment to the Department of surgery at the University of Regensburg and registered in a prospective database. Measures of disease activity and extent, verified pre-operatively and during surgery, were analyzed retrospectively. All surgeries and intraoperative assessments were performed by ten experienced surgeons.
Subgroups were categorized according to age, disease location and behavior (structuring, perforating or the combination of both). General patient characteristics, including family history, general clinical status, medical history (current medication) and preoperative findings, as well as surgical interventions, and immediate surgical outcomes (perioperative complications) were recorded (table 1). Nicotine abuse was defined as any nicotine abuse at the time of surgery.

\section{Diagnostic Techniques}

Leading diagnoses were ascertained instantly before surgery with one or a combination of common diagnostic techniques [range 1-8, median 3 diagnostic techniques], depending on the certainty of the results. Definite diagnoses were obtained with ultrasound (57\%), endoscopy (56\%), intestinal contrast X-ray (50\%), computed tomography (33\%), abdominal X-ray examination (20\%), barium enema (10.6\%), and magnetic resonance imaging (9\%).

Analyses were focused on the determination of the CDAI and the VC. We did depart from the original VC in one instance: patients were classified regardless of first or recurrent surgery for $\mathrm{CD}$ at the time of admission in our unit. Patients without surgical treatment and patients with non-Crohn-related diseases undergoing surgery were excluded from statistical analyses.

Only patients with complete prospectively determined CDAI were considered for analyses. Since the prospective CDAI documentation was incomplete in 50 patients (i.e. patients with exclusively perianal disease), data on VC (174 patients), and CDAI (124 patients) were separately calculated. 
Table 1. Registered data within the patient population

\begin{tabular}{|c|c|c|}
\hline $\begin{array}{l}\text { Patient history and } \\
\text { diagnostic procedures }\end{array}$ & $\begin{array}{l}\text { Preoperative } \\
\text { assessment }\end{array}$ & $\begin{array}{l}\text { Intra-/postoperative } \\
\text { assessment }\end{array}$ \\
\hline $\begin{array}{l}\text { General data } \\
\text { Age } \\
\text { Onset of disease } \\
\text { Gender }\end{array}$ & CDAI & $\begin{array}{l}\text { emergency surgery } \\
\text { elective surgery } \\
\text { repeat surgery } \\
\text { resection/strictureplasty }\end{array}$ \\
\hline $\begin{array}{l}\text { Disease-specific risk factors } \\
\text { Nicotine abuse } \\
\text { NSAID } \\
\text { Oral contraceptives } \\
\text { Mycobacteria tuberculosis } \\
\text { Immunization to measles }\end{array}$ & $\mathrm{VC}$ & $\begin{array}{l}\text { surgery location } \\
\text { stomach } \\
\text { duodenum } \\
\text { jejunum } \\
\text { ileum } \\
\text { ileocecum } \\
\text { ascendending colon }\end{array}$ \\
\hline $\begin{array}{l}\text { Diagnostic procedures } \\
\text { Ultrasound } \\
\text { X-ray abdomen } \\
\text { Small bowel enema } \\
\text { Colonography } \\
\text { CT scan } \\
\text { MRI } \\
\text { Biopsy }\end{array}$ & $\begin{array}{l}\text { disease localizaton } \\
\text { esophageus/stomach } \\
\text { duodenum/jejunum } \\
\text { ileum } \\
\text { ileocecum } \\
\text { ascending colon } \\
\text { transverse colon } \\
\text { descending colon } \\
\text { rectosigmoid colon } \\
\text { perianal disease }\end{array}$ & $\begin{array}{l}\text { descending colon } \\
\text { rectosigmoid colon } \\
\text { preexisting anastomosis } \\
\text { fistula drainage } \\
\quad \text { seton placement } \\
\text { advancement flap } \\
\text { abscess drainage }\end{array}$ \\
\hline & $\begin{array}{l}\text { pre-existing complications } \\
\text { stenosis } \\
\text { ileus } \\
\text { abscess } \\
\text { (intra-/extra-abdominal) } \\
\text { fistulae } \\
\text { entero-enteral } \\
\text { entero-cutaneous } \\
\text { entero-vesical } \\
\text { entero-genital } \\
\text { other } \\
\text { hemorrhage } \\
\text { malignancy }\end{array}$ & $\begin{array}{l}\text { perioperative complications } \\
\text { anastomotic leakage } \\
\text { peritonitis } \\
\text { sepsis } \\
\text { wound infection/ } \\
\quad \text { dehiscence } \\
\text { infection (other) } \\
\text { hemorrhage } \\
\text { bowel obstruction } \\
\text { early recurrence } \\
\text { abscess } \\
\text { fistula } \\
\text { thrombembolic event death }\end{array}$ \\
\hline
\end{tabular}

Note that 170 patients have been analyzed after exclusion of surgical procedures without relation to CD and in 124 patients CDAI data were obtained for statistical evaluation.

\section{Statistical Analyses}

Descriptive and univariate analyses were performed to summarize the data. Categorical variables were compared between subgroups with the $\chi^{2}$ or Fisher's exact test. Correlations among variables were assessed by calculation of the Spearman coefficient. CDAI values were tested for presence of normal distribution and compared with the Student t test or one-way ANOVA.

In a second step, variables were re-evaluated by general multifactorial analysis of variances and stepwise logistic regression. $\mathrm{p}<0.05$ was considered significant. Analyses were carried out with SPSS statistical software, version 13.0 (SPSS ${ }^{\circledR}$ Inc., Chicago, Ill., USA).

Significance of CDAI and Vienna Classification in Surgery

\section{Results}

\section{General Patient Characteristics}

One hundred and ninety-eight patients with the diagnosis of CD were treated in our department between June 1992 and July 2000. The demographic data are summarized in table $2.39 \%$ of the patients had surgery elsewhere previous to admission, $17 \%$ had undergone intestinal resection. No patients were submitted for secondary surgical treatment of postoperative complications.

Dig Surg 2006;23:241-249 
Table 2. General patient characteristics

\begin{tabular}{llc}
\hline Patients admitted, total & & 198 \\
\hline Surgery/medical management & & $177(88.9 \%) / 21(11.1 \%)$ \\
\hline Gender, men:women & & $80: 97$ \\
\hline Age at surgery, years & median, min/max & $\mathrm{M}: 32,5 ; 14 / 61$ \\
& & $\mathrm{~W}: 34,0 ; 16 / 70$ \\
\hline Age at first diagnosis, years & median, min/max & $\mathrm{M}: 25,0 ; 11 / 60$ \\
& & $\mathrm{~W}: 25,0 ; 8 / 57$ \\
\hline Repeat surgery & & $69(39.7 \%)$ \\
\hline Emergency & & $11(6.4 \%)$ \\
\hline Medication before surgery, & & $103(59.2 \%)$ \\
patients & steroids & $17(9.8 \%)$ \\
& azathioprin & $77(44.3 \%)$ \\
& 5-ASA & 0 \\
& anti-TNF & $11(6.3 \%)$ \\
& ciprofloxacin & $17(9.8 \%)$ \\
& metronidazole & $79(45.4 \%)$ \\
\hline
\end{tabular}

Surgical procedures are listed in detail in table 3. In 5 patients, laparotomy was indicated due to causes unrelated to CD. Specifically, indications were (a) mechanical bowel obstruction after prior surgery (3 patients); (b) cholecystitis (1 patient), and (c) an incarcerated incisional hernia (1 patient). These patients were excluded from further analysis. 65 patients presented as emergencies (GI bleeding: 3 patients, Crohn-related mechanical obstruction: 12 patients, intra- or extra-abdominal abscesses: 22 and 28 patients, respectively), 11 of whom required acute surgical therapy. Resections were performed in 138 patients, vs. 15 patients with strictureplasties (two strictureplasties in 2 patients, five in 1 patient; table 3$)$.

\section{Medical Therapy}

Medical therapy prior to surgery included corticosteroids in $59.2 \%$ of the patients, 5 -ASA in $44.3 \%$, azathioprine in $9.8 \%$. No patient received 6-mercaptopurine or anti-TNF- $\alpha$ treatment. $6.3 \%$ were treated with ciprofloxacin and $9.8 \%$ with metronidazole. There were no differences in the CDAI scores of patient groups treated with different medical therapies.

Of note, corticosteroid medication was used in $77 \%$ of the patients with disease location proximal to the ileum (vs. $55 \%$ under corticosteroid therapy overall, $\mathrm{p}=0.03$, $\chi^{2}$ ) and in $71.4 \%$ of the patients with stricturing disease behavior (vs. $53.4 \%$ patients without strictures, $\mathrm{p}=0.02$; $\chi^{2}$ and logistic regression). In contrast, patients without
Table 3. Characterization of surgical procedures and surgical site (multiplicity of sites included)

\begin{tabular}{lc}
\hline & Patients/percentages \\
\hline Emergency surgery & $11 / 6.4$ \\
Elective surgery & $160 / 93.6$ \\
Repeat surgery & $67 / 39$ \\
Resection:strictureplasty & $151 / 82.5: 15 / 8.8$ \\
Stoma (ileostoma) & $8 / 4.7$ \\
Fistula drainage & $13 / 7.6$ \\
Seton placement & $13 / 7.6$ \\
Advancement flap & $2 / 1.2$ \\
Abscess drainage & $22 / 12.9$ \\
\hline Surgical site & \\
Stomach & 0 \\
Duodenum & $2 / 1.2$ \\
Jejunum/ileum & $23 / 13.5$ \\
Ileocecum & $91 / 53.2$ \\
Ascendending colon & $19 / 11.1$ \\
Transverse colon & $17 / 9.9$ \\
Descending colon & $9 / 5.3$ \\
Recto-sigmoid & $27 / 15.8$ \\
Preexisting anastomosis & $13 / 7.6$ \\
\hline
\end{tabular}

$\mathrm{CD}$ proximal to the ileum more frequently received azathioprine ( 22 vs. $7.4 \%$ overall, $p=0.018, \chi^{2}$ ). Ciprofloxacin $(9.5 \%)$ and metronidazole (14\%) were predominately used in patients with intra-abdominal abscess formation $\left(\mathrm{p}<0.006 ; \chi^{2}\right.$ and logistic regression). 
Table 4. Relation between preoperative and intraoperative findings according to the $\mathrm{VC}$ as assessed by $\chi^{2}$ test and Spearman correlation

\begin{tabular}{|c|c|c|c|c|c|c|c|}
\hline \multicolumn{2}{|c|}{$\begin{array}{l}\text { Vienna } \\
\text { classification factor }\end{array}$} & \multicolumn{2}{|c|}{ Presence } & \multicolumn{2}{|c|}{$\begin{array}{l}\text { Surgical intervention } \\
\text { yes/no }\end{array}$} & \multirow{2}{*}{$\begin{array}{c}\chi^{2} \\
<0.0001\end{array}$} & \multirow{2}{*}{$\begin{array}{l}\begin{array}{l}\text { Spearman } \\
\text { correlation }\end{array} \\
0.491\end{array}$} \\
\hline \multirow[t]{8}{*}{ Location } & 1 & yes & 138 & yes & 117 & & \\
\hline & & no & 36 & no & 57 & & \\
\hline & 2 & yes & 98 & yes & 45 & $<0.0001$ & 0.416 \\
\hline & & no & 76 & no & 129 & & \\
\hline & 3 & yes & 97 & yes & 127 & 0.206 & -0.096 \\
\hline & & no & 77 & no & 47 & & \\
\hline & 4 & yes & 27 & yes & 27 & $<0.0001$ & 0.431 \\
\hline & & no & 147 & no & 148 & & \\
\hline \multirow[t]{8}{*}{ Behavior } & 1 & yes & 38 & yes & $100^{\mathrm{a}}$ & 0.005 & 0.231 \\
\hline & & no & 136 & no & 74 & & \\
\hline & 2 & yes & 138 & yes & 138 & 0.002 & 0.277 \\
\hline & & no & 36 & no & 36 & & \\
\hline & 3 & yes & 106 & yes & $67^{\mathrm{b}}$ & $<0.0001$ & 0.620 \\
\hline & & no & 68 & no & 107 & & \\
\hline & $\mathrm{X}$ & yes & 137 & yes & $67^{\mathrm{b}}$ & $<0.0001$ & 0.529 \\
\hline & & no & 37 & no & 107 & & \\
\hline
\end{tabular}

a Surgical interventions without fistula excision or abscess drainage.

${ }^{\mathrm{b}}$ Exclusively surgical interventions with fistula excision or abscess drainage.

$\mathrm{X}=$ Combined structuring and perforating disease behaviour, not classifiable in VC.

\section{Age/Gender}

The median age of our study group (95 women and 79 men) at the time of surgery was 34.0 years (17-62) and 31.5 years (17-58), respectively. $27.6 \%$ were older than 40 years and $9.2 \%$ younger than 20 years. At primary diagnosis, $14.9 \%$ of the patients were older than 40 years. CDAI levels were equal in both age groups (see table 5). In addition, no significant relation between age $(</ \geq 40$ years, classification parameter A) and preoperative disease location (classification parameter $\mathrm{L}$ ) was detectable. Nevertheless, higher age was associated with an elevated ratio of patients with stricturing disease (50 vs. $25.4 \%$, $\mathrm{p}=0.002$; Spearman correlation 0.235 ). Gender had no impact on the investigated parameters.

\section{Location of Disease}

Location 1 (ileum plus spillover to cecum) was diagnosed in the majority of the patients $(\mathrm{n}=139)$. This number includes patients who had a previous ileocecal resection. All 97 patients, who presented with colon involvement, had a diseased terminal ileum (L3). CD spreading proximal to the ileum was detectable in 27 patients. In all regions, the primarily diagnosed disease location revealed a significant relation with the surgically treated locations ( $\mathrm{p}<0.0001$; table 4$)$. This was reconfirmed by stepwise logistic regression. However, the Spearman co- efficients revealed weak positive correlations between pre- and intraoperatively determined locations (table 4).

Stratification of the patients into the four VC disease location subgroups revealed no differences in CDAI. However, multiplicity of disease locations was accompanied by a high CDAI variation. CDAI levels ranged between 223.3 \pm 25.4 and $425.0 \pm 24.8$ for subgroups with $1-5$ or more sites of surgery and a significantly higher CDAI was associated with 5 vs. 3 locations $\left(p=0.07, \chi^{2}\right)$. Since certain patient subgroups obviously required a different intensity of medical treatment, we hypothesized that the CDAI may vary in VC subgroups. However, no differences in CDAI values were observed in the $\mathrm{VC}$ location subgroups.

\section{Behavior of Disease}

56 patients presented with stricturing vs. 105 patients with penetrating disease behavior. 37 patients showed neither strictures nor penetrations. However, 24 patients had combinations of strictures and penetrations, and were, therefore, not represented by the VC. As expected, significantly $(\mathrm{p}<0.001)$ more strictureplasties were performed in patients with stricturing disease behavior and with involvement of the upper gastrointestinal tract (vs. other bowel regions) (table 4). Interestingly, stratification according to behavior factors (3) revealed an elevated CDAI (463 \pm 21 , table 5$)$ in patients with the simultane- 
Table 5. CDAI variations in dependence of clinical situation

\begin{tabular}{|c|c|c|c|c|}
\hline Clinical situation & Status & & CDAI & $\mathrm{p}$ value \\
\hline \multirow[t]{2}{*}{ Age $<40$ years } & yes & & $242 \pm 14$ & \multirow[t]{2}{*}{0.29} \\
\hline & no & & $279 \pm 28$ & \\
\hline \multirow[t]{2}{*}{ VC location 4} & yes & & $263 \pm 41$ & \multirow[t]{2}{*}{0.91} \\
\hline & no & & $249 \pm 13$ & \\
\hline \multirow[t]{2}{*}{ VC behavior 3} & yes & & $256 \pm 18$ & \multirow[t]{2}{*}{0.79} \\
\hline & no & & $243 \pm 17$ & \\
\hline \multirow[t]{2}{*}{ Ileus } & yes & & $271 \pm 51$ & \multirow[t]{2}{*}{0.67} \\
\hline & no & & $249 \pm 13$ & \\
\hline \multirow[t]{2}{*}{ Presence of fistulas } & yes & & $255 \pm 19$ & \multirow[t]{2}{*}{0.89} \\
\hline & no & & $246 \pm 16$ & \\
\hline \multirow{4}{*}{$\begin{array}{l}\text { Multiple independent } \\
\text { fistula systems }\end{array}$} & yes & 1 system & $253 \pm 21$ & \multirow{4}{*}{0.128} \\
\hline & & 2 systems & $227 \pm 52$ & \\
\hline & & 3 or more s. & $463 \pm 21$ & \\
\hline & no & & $246 \pm 16$ & \\
\hline \multirow{3}{*}{$\begin{array}{l}\text { Extraintestinal } \\
\text { manifestation }\end{array}$} & yes & 1 location & $255 \pm 29$ & \multirow{3}{*}{0.293} \\
\hline & & 2 locations & $393 \pm 110$ & \\
\hline & no & & $244 \pm 13$ & \\
\hline \multirow[t]{2}{*}{ Surgery upper GI tract } & yes & & $280 \pm 35$ & \multirow[t]{2}{*}{0.32} \\
\hline & no & & $245 \pm 13$ & \\
\hline \multirow[t]{4}{*}{ Surgery colon } & yes & 1 site & $277 \pm 33$ & \multirow[t]{4}{*}{0.125} \\
\hline & & 2 & $345 \pm 50$ & \\
\hline & & 3 or more & $369 \pm 75$ & \\
\hline & no & & $229 \pm 14$ & \\
\hline \multirow[t]{6}{*}{ Surgery multiple sites } & yes & 1 & $246 \pm 18$ & \multirow{6}{*}{$\begin{array}{l}0.07 \text { ( } 5 \text { vs. } 1 \\
\text { site) and } 0.04 \\
(5 \text { vs. } 3 \text { sites) }\end{array}$} \\
\hline & & 2 & $261 \pm 30$ & \\
\hline & & 3 & $223 \pm 25$ & \\
\hline & & 4 & $241 \pm 51$ & \\
\hline & & 5 or more & $425 \pm 25$ & \\
\hline & no & & 212 (2 pat.) & \\
\hline \multirow[t]{2}{*}{ Emergency } & yes & & $207 \pm 43$ & \multirow[t]{2}{*}{0.431} \\
\hline & no & & $253 \pm 13$ & \\
\hline
\end{tabular}

CDAI given as mean \pm SEM, p values calculated by use of Student's $t$ test or one-way ANOVA after rank transformation of non-normally distributed CDAI values. Note that none of the factors had any impact on short-term postoperative outcome. ous presence of three or more different fistulae (i.e. enterocutaneous plus enteroenteral plus enterovaginal), however without significance in comparison to patients with less than three fistulae.

\section{Extent of Surgery}

101 patients (58\%) revealed a multifocal disease pattern (2-6 locations) that could not be represented by a precise VC categorization.
When the CDAI was analyzed according to the extent of surgical therapy, only the necessity of surgery at more five or more vs. three locations (resection and strictureplasty) was associated with a markedly higher score (table 5).

\section{Perioperative Complications}

No lethal complications were noted. Perioperative complications (table 6) occurred in $10.5 \%$ of the patients, with $4.1 \%$ displaying anastomotic leakage. Three patients 
Table 6. Perioperative complications

\begin{tabular}{lc}
\hline Complication & $\begin{array}{c}\text { Number/ } \\
\text { percent }\end{array}$ \\
\hline Anastomotic leakage & $7 / 4.1$ \\
Peritonitis & $3 / 1.8$ \\
Sepsis & $0 / \mathrm{ND}$ \\
Wound infection/dehiscence & $2 / 1.2$ \\
Infection (other) & $7 / 4.0$ \\
Hemorrhage & $0 / \mathrm{ND}$ \\
Bowel obstruction & $0 / \mathrm{ND}$ \\
Early recurrence & \\
$\quad$ Abscess & \\
$\quad$ Fistula & $2 / 1.2$ \\
Thrombembolic event & $1 / 0.6$ \\
Death & $0 / \mathrm{ND}$ \\
\hline Total & $22 / 13.2$ \\
\hline
\end{tabular}

(1.8\%) developed a generalized peritonitis. Early fistula recurrence appeared in $2(1.2 \%)$ and wound dehiscence in $4(2.4 \%)$ patients. Half of the patients with complications presented with two or more complications at once.

The average CDAI of patients with complications (overall $340.9 \pm 27.9)$ and with complications requiring revision surgery (353.2 \pm 34.9$)$ was elevated in comparison to patients without complications $(240.2 \pm 13.6, \mathrm{p}<0.05)$. Analogously, patients with postoperative anastomotic leakage revealed significantly elevated CDAI levels (357.1 \pm 36.9 vs. $244.4 \pm 13.2, \mathrm{p}<0.05)$. However, multivariate calculations abolished the significant differences in CDAI in patients with or without postoperative complications.

$\chi^{2}$ calculations showed significant $(\mathrm{p}<0.05)$ associations of VC behavior types 1,3 , and combined stricturing plus perforating disease with later perioperative complications. Moreover, corticoid medication $(p=0.025)$, resection surgery performed at the ileocecal region $(\mathrm{p}=0.02)$, combined disease pattern (0.24) and nicotine abuse $(\mathrm{p}=$ 0.003 ) were significantly associated with anastomotic leakage. After stepwise logistic regression, however, nicotine abuse remained the only significant variable increasing the risk for postoperative anastomotic leakage $(\mathrm{p}=0.037)$ and perioperative complications in general $(\mathrm{p}=0.004)$.

\section{Discussion}

In the present study we evaluated, the usefulness of the 'VC' and the 'CDAI', when applied preoperatively to CD patients, in predicting the extent and type of surgery re- quired and the risk of early surgical complications. Both instruments have been predominately applied to patients who are treated medically, but not surgically [3-5].

In general, quantification of $\mathrm{CD}$ activity may be problematic, due to the frequently complex disease appearance. Any information about the disease aggression would be useful for a multimodal treatment concept including medical pretreatment, surgical strategy and postoperative maintenance therapy, balancing quality of life [14], requirement of side effect charged drug therapy vs. the probability for surgery $[10,15,16]$, including the risk of recurrence and re-operation $[10,17]$. Precise information on the surgery-associated risk is of fundamental importance to the patient [2].

The examined classifications are based on different types of Crohn's-associated data, and are therefore not comparable. Whereas the CDAI includes numerous subjective and clinical data (vital parameters, body weight, abscess/intra-abdominal mass), the VC focuses on morphological characteristics of the disease. Therefore, we presumed that by quantificating the CDAI in certain VC subgroups we would be most likely to identify patient subgroups with increased CDAI, who were particularly prone to increased disease extent and perioperative risk.

Preoperative medical therapy, i.e. corticosteroids, may decrease disease activity and subjective complaints, and therefore, interfere with the reliability of the VC and the CDAI. Bowel strictures and inflammatory changes may rapidly resolve $[12,18]$, which may change the phenotypic disease appearance [9]. Since nearly $60 \%$ of our patients received steroids preoperatively, we cannot exclude that drug treatment interfered our observations. However, the diagnostic procedures in our study immediately preceded surgery, and the majority of patients with different intra- vs. preoperative disease extent and location consistently revealed more diseased locations intraoperatively. Furthermore, since corticosteroid therapy had no effect on the CDAI in our patients, it is unlikely that corticosteroids acted as disease-resolving agent and significantly affected our results. The evidently low number of patients on azathioprine at the time of surgery in our study may be explained by our center policy with restrictive use of azathioprine (and 6-mercaptopurine) and complete avoidance of anti-TNF treatment for remission maintenance therapy [19].

Younger, as well as older, age at first diagnosis has been identified as risk factor for CD recurrence, reflecting general disease activity [17]. However, numerous large studies failed to show any influence of age on disease recurrence $[16,20,21]$. In our study, as well, we found no as- 
sociations with age and the other VC classification factors, or with CDAI levels. Reducing the cut-off value of the VC from 40 to 20 years of age, as proposed earlier [17], had no influence on the findings.

$\mathrm{CD}$ activity may be determined by disease location, multiplicity of locations, disease behavior (perforating/ fistulizing), and inflammatory activity [16, 22-26]. Both, the VC and CDAI, would thus theoretically allow a prediction of intraoperative findings. However, our analyses revealed no associations between the VC or the CDAI and intraoperative findings. Although a larger number of locations requiring surgical therapy ( 5 vs. 3 ), was reflected by an elevation of the CDAI, this trend was not linear, since no progressive increase in the CDAI was notable from 1 to 5 locations. Furthermore, patients displaying complex disease patterns with more than two independent fistulae revealed higher CDAI levels than those with single fistula. However, an aggressive disease type might be presumed in patients with $\mathrm{CD}$ manifestation in five different locations or with complex fistula combinations without the use of a special classification.

Although the analyses of VC categories revealed significant associations between pre- and intraoperative locations, correlations were weak, as indicated by a low Spearman coefficient. Moreover, these associations could have been expected without special classification. In addition, a clear allocation into the subgroups of the $\mathrm{VC}$ is not possible in patients with combined fistulizing and stricturing disease, which was present in the vast majority $(78 \%)$ of patients.

Furthermore, the extent of CD surgery may be anticipated by clinical data included in the CDAI, such as WBC count and fever, abdominal mass, and the presence of abscesses/fistulae. We therefore evaluated the CDAI in patient subgroups, reflecting risk constellations for increased CD aggression [27, 28]. Although elevated CDAI scores $(>200)$ were recognizable in the majority of the subgroups, no disease 'subtype' except 'multiple independent fistulae' was associated with significantly elevated CDAI values. This finding is not surprising, since 'subjective well-being' is considerably influenced by the presence of fistulas [14]. Both 'subjective well-being' and the presence of abscess/fistulae are heavily weighted factors $(\times 7$ and $\times 20$; fig. 1$)$ within the CDAI.

Surgical therapy prior to the VC and CDAI staging may have biased our results, since the specificity of diagnostic techniques preoperatively may be altered [13], and anastomoses may mature into restenoses. However, comparison of the CDAI's of patients with or without preceding surgery showed no statistical difference.
As mentioned previously, the number of strictures is often underestimated by radiographic as compared to surgical findings in CD patients [13]. Peristalsis and widening as well as distension or adhesions of the intestinal tract may mislead the examiner, who may furthermore focus on the most dominant lesion, causing him to direct less attention towards other findings [13]. Although in our study diagnoses relied on combined techniques including endoscopy, radiographic examinations, CT, MRT and ultrasound, we frequently (54.4\%) found that while only a single site was diagnosed preoperatively, more sites actually required surgical therapy.

Since we had found that pre-operative classifications did not predict intraoperative disease extent in CD patients, we sought to determine whether preoperative findings could predict early postoperative complications [2830]. With univariate comparisons, we confirmed that the following established risk factors: complex disease pattern, ileocecal resection, corticoid medication and nicotine abuse were significantly related to postoperative complications. The low overall number of complications in our study, however, may lead to underrating of relations to certain VC subfactors. Slightly elevated CDAI levels were observed along with postoperative complications, infectious complications, anastomotic leakage and pre-existing bowel obstruction. This is in agreement with the general concept that an exaggerated disease accompanies an increased perioperative risk [27]. In multivariate analyses, nicotine abuse remained the only predictive factor associated with an elevated risk for perioperative complications and anastomotic leakage, which is in accordance with the previously observed heightened risk of disease recurrence in smokers [31].

Together, the VC and the CDAI may be useful for monitoring disease activity under conservative therapy. However, they are less useful for surgical therapy planning and perioperative risk prediction. Nicotine abuse, which emerged as the most relevant risk factor for perioperative complications, for instance, does not contribute to any classification. Indications for surgery should depend on disease extent and activity, on refractoriness to medical therapy, and on pre-existing complications, such as bowel obstruction, perforation, hemorrhage, abscess formation, toxic megacolon and endoscopic proof of high-grade dysplasia [10, 14, 16, 32]. 


\section{References}

1 Mekhjian HS, Switz DM, Melnyk CS, Rankin GB, Brooks RK: Clinical features and natural history of Crohn's disease. Gastroenterology 1979;77:898-906

2 Kiran RP, Delaney CP, Senagore AJ, O'BrienErmlich B, Mascha E, Thornton J, Fazio VW: Prospective assessment of Cleveland Global Quality of Life (CGQL) as a novel marker of quality of life and disease activity in Crohn's disease. Am J Gastroenterol 2003;98:17831789.

3 Best WR, Becktel JM, Singleton JW: Rederived values of the eight coefficients of the Crohn's Disease Activity Index (CDAI). Gastroenterology 1979;77:843-846.

4 Best WR, Becktel JM, Singleton JW, Kern F Jr: Development of a Crohn's disease activity index. National Cooperative Crohn's Disease Study. Gastroenterology 1976;70:439444

5 Veloso FT, Ferreira JT, Barros L, Almeida S: Clinical outcome of Crohn's disease: analysis according to the Vienna classification and clinical activity. Inflamm Bowel Dis 2001;7: 306-313.

6 Goebell H, Wienbeck M, Schomerus H, Malchow $\mathrm{H}$ : Evaluation of the Crohn's Disease Activity Index (CDAI) and the Dutch Index for severity and activity of Crohn's disease: an analysis of the data from the European Cooperative Crohn's Disease Study. Med Klin (Munich) 1990;85:573-576.

7 Sands BE, Anderson FH, Bernstein CN, Chey WY, Feagan BG, Fedorak RN, Kamm MA, Korzenik JR, Lashner BA, Onken JE, Rachmilewitz D, Rutgeerts P, Wild G, Wolf DC, Marsters PA, Travers SB, Blank MA, van Deventer SJ: Infliximab maintenance therapy for fistulizing Crohn's disease. N Engl J Med 2004;350:876-885.

8 Rutgeerts P, Feagan BG, Lichtenstein GR, Mayer LF, Schreiber S, Colombel JF, Rachmilewitz D, Wolf DC, Olson A, Bao W, Hanauer SB: Comparison of scheduled and episodic treatment strategies of infliximab in Crohn's disease. Gastroenterology 2004; 126:402-413.

9 Louis E, Collard A, Oger AF, Degroote E, Aboul Nasr El Yafi FA, Belaiche J: Behaviour of Crohn's disease according to the Vienna classification: changing pattern over the course of the disease. Gut 2001;49:777-782.
10 Dirks E, Goebell H, Schaarschmidt K, Forster S, Quebe FE, Eigler FW: Clinical relapse of Crohn's disease under standardized conservative treatment and after excisional surgery. Dig Dis Sci 1989;34:1832-1840.

11 Lichtenstein GR, Yan S, Bala M, Blank M, Sands BE: Infliximab maintenance treatment reduces hospitalizations, surgeries, and procedures in fistulizing Crohn's disease. Gastroenterology 2005;128:862-869.

12 Shepherd HA, Barr GD, Jewell DP: Use of an intravenous steroid regimen in the treatment of acute Crohn's disease. J Clin Gastroenterol 1986;8:154-159.

13 Otterson MF, Lundeen SJ, Spinelli KS, Sudakoff GS, Telford GL, Hatoum OA, Saeian K, Yun H, Binion DG: Radiographic underestimation of small bowel stricturing Crohn's disease: a comparison with surgical findings. Surgery 2004;136:854-860.

14 Post S, Kunhardt M, Herfarth C: Subjective assessment of quality of life, pain and surgical success after laparotomy for Crohn disease. Chirurg 1995;66:800-806.

15 Bernell O, Lapidus A, Hellers G: Risk factors for surgery and postoperative recurrence in Crohn's disease. Ann Surg 2000;231:38-45.

16 Raab Y, Bergstrom R, Ejerblad S, Graf W, Pahlman L: Factors influencing recurrence in Crohn's disease: an analysis of a consecutive series of 353 patients treated with primary surgery. Dis Colon Rectum 1996;39: 918-925.

17 Post S, Herfarth C, B'hm E, Timmermanns G, Schumacher H, Schuermann G, Golling $\mathrm{M}$ : The Impact of disease pattern, surgical management, and individual surgeons on the risk for relaparotomy for recurrent Crohn's disease. Ann Surg 1996;223:253260.

18 Murch SH, Walker Smith JA: Medical management of chronic inflammatory bowel disease. Baillieres Clin Gastroenterol 1994;8: 133-148.

19 Scholmerich J: Prevention of Crohn disease recurrence. Chirurg 1998;69:908-914.

20 Speranza V: Risk factors for recurrence of Crohn disease after intestinal resection. Chirurg 1995;66:751-756.
21 Wettergren A, Christiansen J: Risk of recurrence and reoperation after resection for ileocolic Crohn's disease. Scand J Gastroenterol 1991;26:1319-1322.

22 Michelassi F, Balestracci T, Chappell R, Block GE: Primary and recurrent Crohn's disease: experience with 1,379 patients. Ann Surg 1991;214:230-238.

23 Whelan G, Farmer RG, Fazio VW, Goormastic M: Recurrence after surgery in Crohn's disease: relationship to location of disease (clinical pattern) and surgical indication. Gastroenterology 1985;88:1826-1833.

24 Heimann TM, Greenstein AJ, Lewis B, Kaufman D, Heimann DM, Aufses AHJ: Prediction of early symptomatic recurrence after intestinal resection in Crohn's disease. Ann Surg 1993;218:294-298.

25 Greenstein AJ, Lachman P, Sachar DB, Springhorn J, Heimann T, Janowitz HD, Aufses AH Jr: Perforating and non-perforating indications for repeated operations in Crohn's disease: evidence for two clinical forms. Gut 1988;29:588-592.

26 Aeberhard P, Berchtold W, Riedtmann HJ, Stadelmann G: Surgical recurrence of perforating and nonperforating Crohn's disease: a study of 101 surgically treated patients. Dis Colon Rectum 1996;39:80-87.

27 Yamamoto T, Allan RN, Keighley MR: Risk factors for intra-abdominal sepsis after surgery in Crohn's disease. Dis Colon Rectum 2000;43:1141-1145.

28 Post S, Betzler M, von Ditfurth B, Schurmann G, Kuppers P, Herfarth C: Risks of intestinal anastomoses in Crohn's disease. Ann Surg 1991;213:37-42.

29 Yamamoto T, Keighley MR: Factors affecting the incidence of postoperative septic complications and recurrence after strictureplasty for jejunoileal Crohn's disease. Am J Surg 1999;178:240-245.

30 Yamamoto T, Keighley MR: Smoking and disease recurrence after operation for Crohn's disease. Br J Surg 2000;87:398-404.

31 Yamamoto T: Factors affecting recurrence after surgery for Crohn's disease. World J Gastroenterol 2005;11:3971-3979.

32 Friedman S, Rubin PH, Bodian C, Goldstein E, Harpaz N, Present DH: Screening and surveillance colonoscopy in chronic Crohn's colitis. Gastroenterology 2005; 120:820826 